\title{
Novel Design of Fractal Antenna using Giuseppe Peano Geometry for Wireless Applications
}

\author{
Gaurav Pal Singh \\ M.Tech Scholar \\ Electronics and Communication Engineering Deptt. \\ Amritsar College of Engineering and Technology, \\ Amritsar
}

\author{
Narinder Sharma \\ Associate Professor \\ Electronics and Communication Engineering Deptt. \\ Amritsar College of Engineering and Technology, \\ Amritsar
}

\begin{abstract}
A novel design of fractal using Giuseppe Peano geometry for wireless applications has been presented in this paper. Low cost FR4 glass epoxy substrate with $1.6 \mathrm{~mm}$ thickness and dielectric constant 4.4 is used to design proposed antennas. The resonant frequency used for calculating the dimensions of proposed antenna is $4 \mathrm{GHz}$. Three iterations of proposed antenna are designed to achieve the miniaturization. Antenna is designed and simulated by using HFSS V13 software and different parameters such as return loss, VSWR, gain has been observed and analyzed. The proposed antenna is useful for different wireless applications as per FCC standards such as bluetooth $(2.12-2.95 \mathrm{GHz})$, WLAN $(4.82-595 \mathrm{GHz})$, high speed wireless communication $(5.92 \mathrm{GHz}-8.5 \mathrm{GHz})$ and $\mathrm{X}$ band for satellite communication $(8-12 \mathrm{GHz})$.
\end{abstract}

\section{Keywords}

Giuseppe Peano, WLAN, FR4, VSWR, HFSS.

\section{INTRODUCTION}

Patch antenna is a conducting plate which consists over the top of a dielectric substrate and the ground plane at the bottom plane of the substrate. The radiator of these antennas is of different shapes and feed by various methods [4] [5]. Microstrip patch antennas are used in different wireless applications due to their compact size and low cost [8]. There are many disadvantages also faced by the microstrip antennas such as low gain, low efficiency, less number of operating frequency bands and less bandwidth [6]. But, the major disadvantage of antenna is that, while designing the antenna as the frequency of antenna decreases the size of patch increases. To overcome this problem the miniaturization techniques are employed to reduce the resonant frequency as well as the size of antenna [9]. The efficient way to reduce the size and resonant frequency of antenna is to introduce the slots in the geometry of patch or ground, use the defected ground structure and apply the different fractal geometries to the patch of antenna [10].

Fractal geometries are applied in the patch antennas to overcome the drawbacks of patch antennas as discussed above [1]. These geometrical shapes are self-similar and repeat themselves at different scales. B. Mandelbort proposed the fractal geometry in 1975 [7]. Two types of properties are used to design the fractal geometries such as self-similarity and space-filling. These two properties make the antenna to work at more number of resonant frequencies with high value of gain [2] [3]. Fractal antennas can be useful for different wireless applications as per FCC standards such as WLAN at 5.15-8.825GHz, WiMAX at 3.3-3.7GHz, X-band for satellite communication at $7.25-8.395 \mathrm{GHz}$ etc [11].

\section{ANTENNA DESIGN}

Initially, a rectangular patch is used to design the geometry of proposed antenna. The dimensions (length and width) of the patch are calculated by using equation (1) to (5) and found to be $17 \mathrm{~mm}$ and $23 \mathrm{~mm}$ respectively. To draw the proposed fractal antenna, Giuseppe Peano geometry is applied along the length (L) and width (W) of the rectangular patch as shown in Figure 1. Line feeding technique is applied to provide the excitation to antenna. $0^{\text {th }}, 1^{\text {st }}$ and $2^{\text {nd }}$ iteration of proposed antenna is shown in Figure 2, Figure 3 and Figure 4 respectively. Parametric values of designed antenna are shown in Table 1.

$$
\begin{aligned}
& w=\frac{c}{2 f o \sqrt{\frac{\varepsilon_{r}+1}{2}}} \\
& \varepsilon_{\text {reff }}=\frac{\varepsilon_{r}+1}{2}+\frac{\varepsilon_{r}-1}{2}\left[1+12 \frac{h}{w}\right]^{\frac{1}{2}} \\
& L_{\text {efff }}=\frac{c}{2 f o \sqrt{\varepsilon_{\text {reff }}}} \\
& \Delta L=0.412 h \frac{\left(\varepsilon_{\text {reff }}+0.3\right)\left(\frac{w}{h}+0.246\right)}{\left(\varepsilon_{\text {reff }}-0.258\right)\left(\frac{w}{h}+0.8\right)} \\
& L=L_{\text {eff }}+2 \Delta L
\end{aligned}
$$

Where,

$c=$ Velocity of light in free space.

$h=$ Substrate height.

$\varepsilon_{r}=$ Relative permittivity of the substrate

$W=$ Width of rectangular patch.

$L=$ Length of rectangular patch.

$L_{\text {eff }}=$ Effective length.

$\varepsilon_{e f f}=$ Effective dielectric constant.

$f_{o=}$ Resonant frequency.

$\Delta L=$ Length extension. 


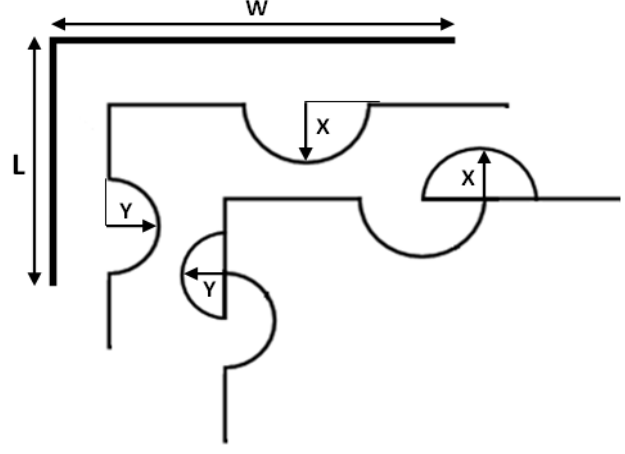

Figure 1: Procedure for designing the iterations of proposed antenna

$0^{\text {th }}$ iteration of the proposed antenna starts with the rectangular geometry with length $(\mathrm{L}=17 \mathrm{~mm})$ and width $(\mathrm{W}=23 \mathrm{~mm})$ as shown in Figure 2. The $1^{\text {st }}$ iteration of antenna is designed by extracting the semi-circular slots along the length and width of the rectangular patch, with radius $X=3.83 \mathrm{~mm}$ and $\mathrm{Y}=2.83 \mathrm{~mm}$ respectively as shown in Figure $3.2^{\text {nd }}$ iteration of proposed antenna is designed by taking the $1^{\text {st }}$ iteration as a base geometry. The semi-circular elements with radius $\mathrm{X}=3.83 \mathrm{~mm}$ and $\mathrm{Y}=2.83 \mathrm{~mm}$ are united along the length and width of rectangular patch respectively as shown in Figure 4.

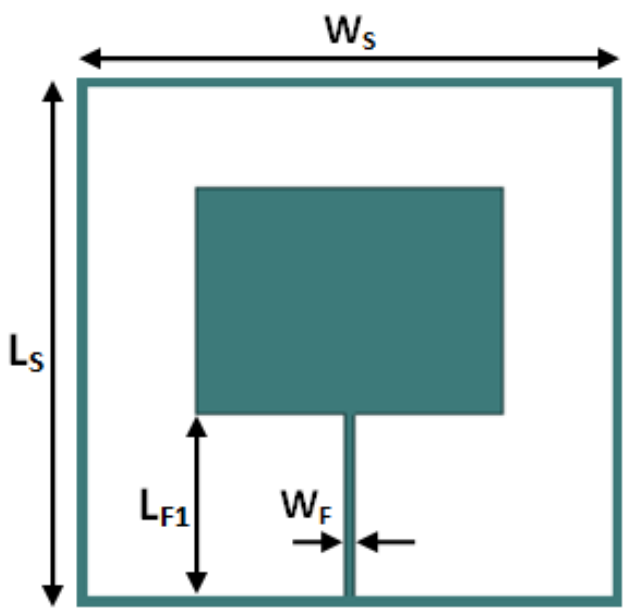

Figure 2: $0^{\text {th }}$ iteration of proposed antenna

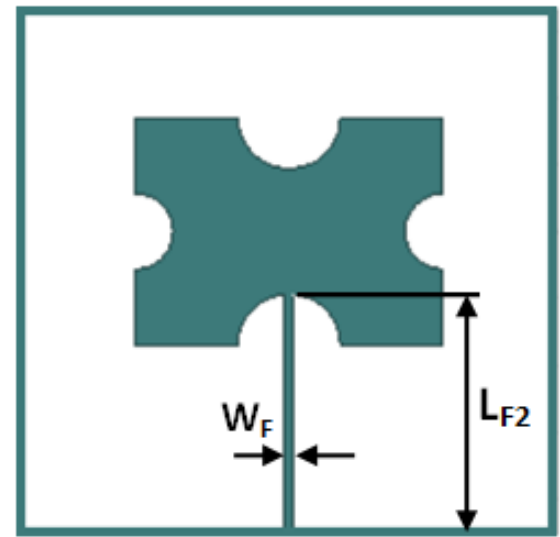

Figure 3: $1^{\text {st }}$ iteration of proposed antenna

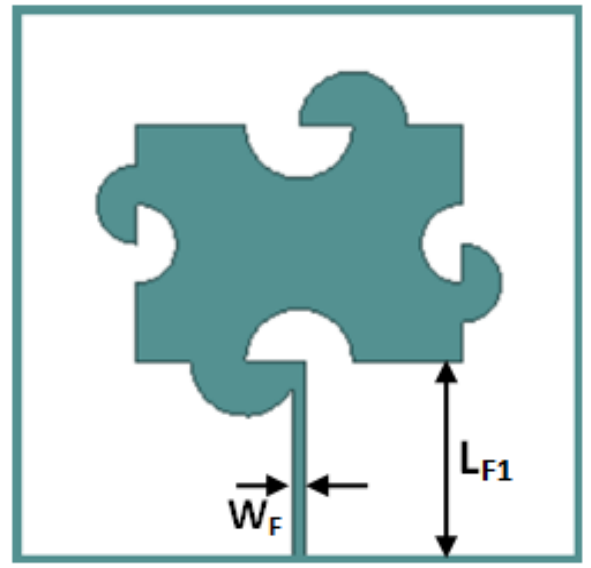

Figure 4: $2^{\text {nd }}$ iteration of proposed antenna

Table 1: Parametric values of proposed antenna

\begin{tabular}{|c|c|c|c|}
\hline S. No. & Parameters & Description & Values \\
\hline 1. & $\mathrm{~W}_{\mathrm{S}}$ & Width of Substrate & $40 \mathrm{~mm}$ \\
\hline 2. & $\mathrm{~L}_{\mathrm{S}}$ & Length of Substrate & $38.92 \mathrm{~mm}$ \\
\hline 3. & $\mathrm{~W}_{\mathrm{F}}$ & Width of Feed Line & $0.60 \mathrm{~mm}$ \\
\hline 4. & $\mathrm{~L}_{\mathrm{F} 1}$ & Length of Feed Line 1 & $17.77 \mathrm{~mm}$ \\
\hline 5. & $\mathrm{~L}_{\mathrm{F} 2}$ & Length of Feed Line 2 & $13.96 \mathrm{~mm}$ \\
\hline
\end{tabular}

\section{RESULT AND DISCUSSIONS}

3.1 Return loss

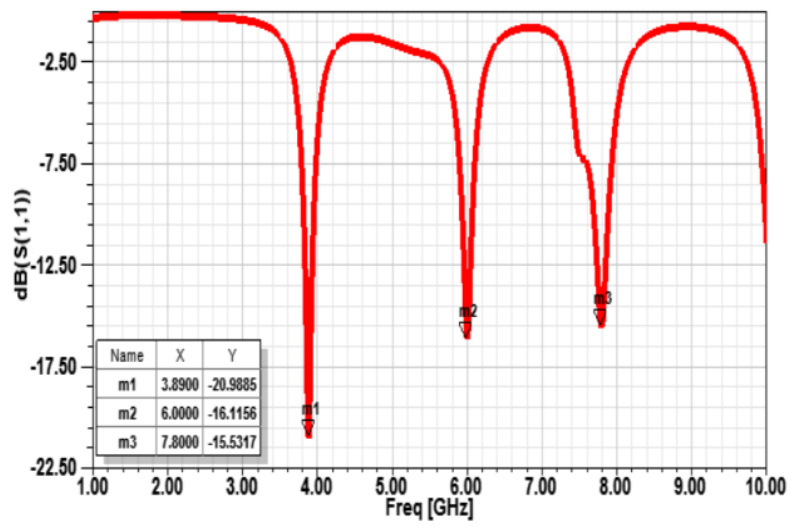

Figure 5: Return loss plot for $0^{\text {th }}$ iteration of proposed antenna

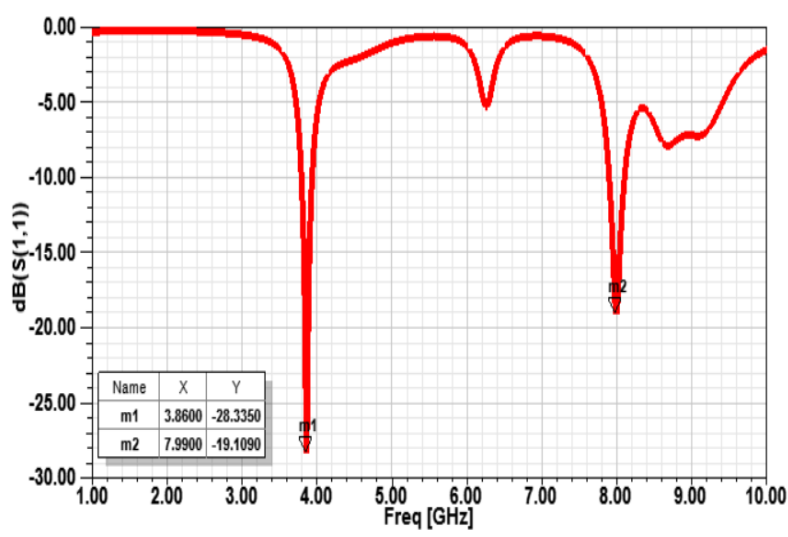

Figure 6: Return loss plot for $1^{\text {st }}$ iteration of proposed antenna 


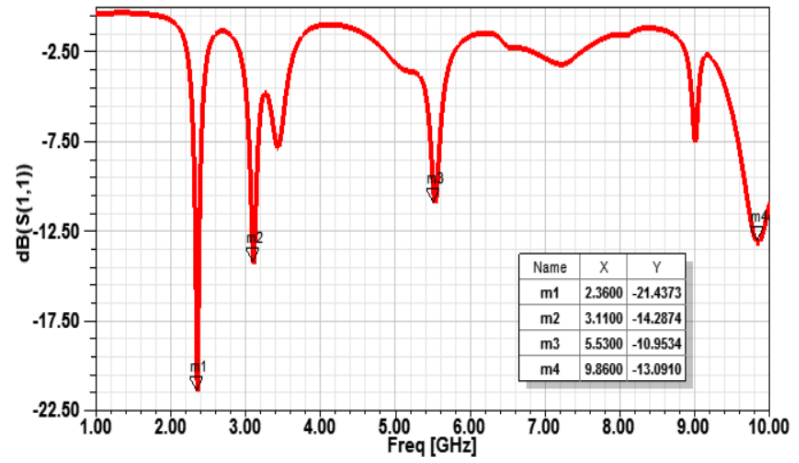

Figure 7: Return loss plot for $2^{\text {nd }}$ iteration of proposed antenna

The $S_{11}$ characteristics (return loss) of the simulated structures of proposed antenna are depicted in Figure 5, Figure 6 and Figure 7 respectively. For the results, it is evident that the $0^{\text {th }}$ iteration of antenna operates on three frequencies, $1^{\text {st }}$ iteration of antenna works on two frequencies and the $2^{\text {nd }}$ iteration of antenna operates on four resonant frequencies. The values of the return losses for all the frequency bands of proposed antenna is at acceptable level $\left(\mathrm{S}_{11}=-10 \mathrm{~dB}\right)$. Simulated values of return loss for all the iterations are shown in Table 2.

\subsection{VSWR}

Voltage Standing Wave Ratio is the measure of mismatch between the patch and the feed line. More the mismatch means more value of VSWR. The acceptable value of VSWR for antenna to be used for practical application is $\leq 2$. Values of VSWR for all iterations at different frequencies are at acceptable level and are shown in Table 2. Simulated VSWR plot for $0^{\text {th }}, 1^{\text {st }}$ and $2^{\text {nd }}$ iterations are shown in Figure 8, Figure 9 and Figure 10 respectively.

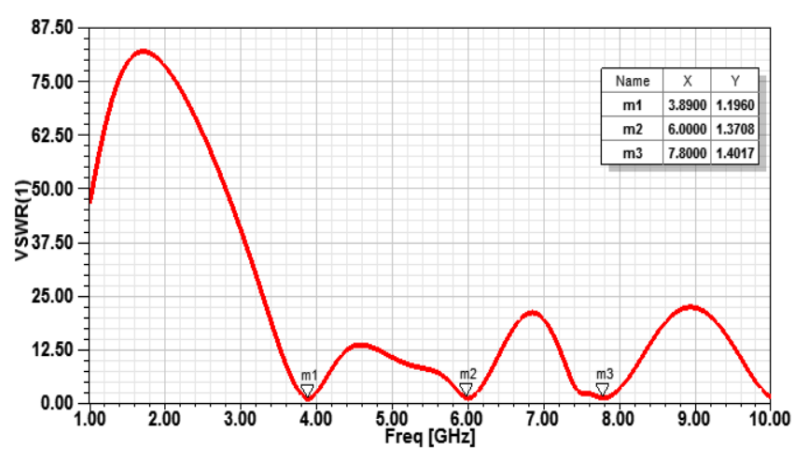

Figure 8: VSWR plot for $0^{\text {th }}$ iteration of proposed antenna

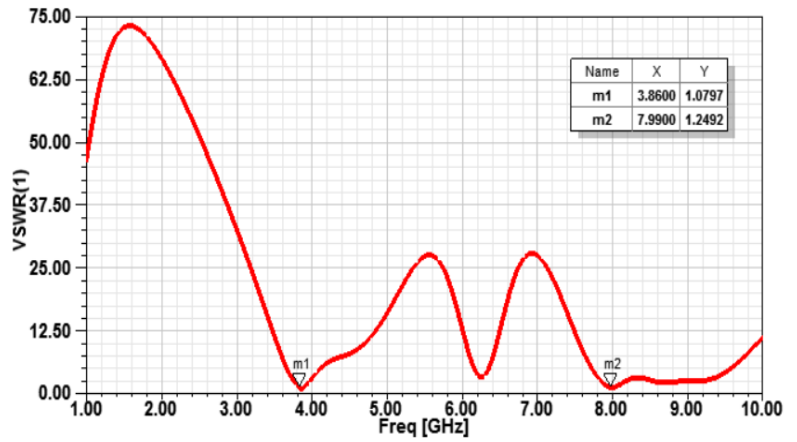

Figure 9: VSWR plot for $1^{\text {st }}$ iteration of proposed antenna

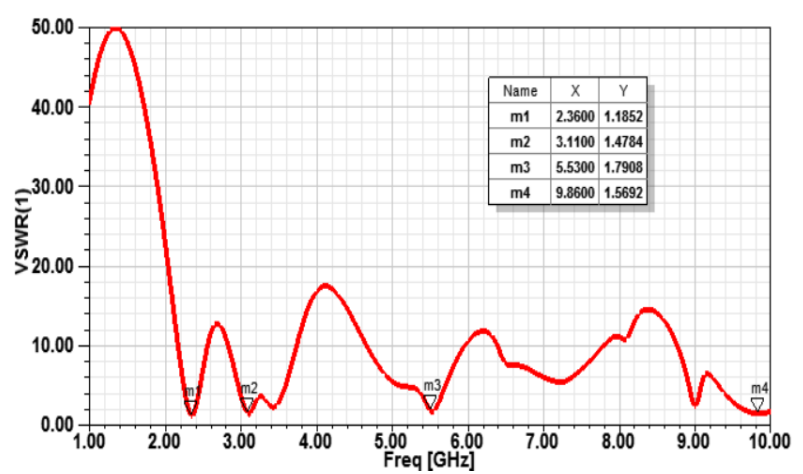

Figure 10: VSWR plot for 2nd iteration of proposed antenna

Table 2. Simulated results of proposed antenna

\begin{tabular}{|c|c|c|c|}
\hline Iteration & $\begin{array}{c}\text { Frequency } \\
\text { in GHz }\end{array}$ & $\begin{array}{c}\text { Return Loss in } \\
\text { dB }\end{array}$ & VSWR \\
\hline \multirow{3}{*}{$\begin{array}{c}0^{\text {th }} \\
\text { iteration }\end{array}$} & 3.89 & -20.98 & 1.19 \\
\hline & 6.00 & -16.11 & 1.37 \\
\hline & 7.80 & -15.53 & 1.40 \\
\hline \multirow{2}{*}{$\begin{array}{c}1^{\text {st }} \\
\text { iteration }\end{array}$} & 3.86 & -28.33 & 1.07 \\
\hline & 7.99 & -19.10 & 1.24 \\
\hline \multirow{4}{*}{$\begin{array}{c}2^{\text {nd }} \\
\text { iteration }\end{array}$} & 2.36 & -21.43 & 1.18 \\
\hline & 3.11 & -14.28 & 1.47 \\
\hline & 5.53 & -10.95 & 1.79 \\
\hline & 9.86 & -13.09 & 1.56 \\
\hline
\end{tabular}

\subsection{Gain}
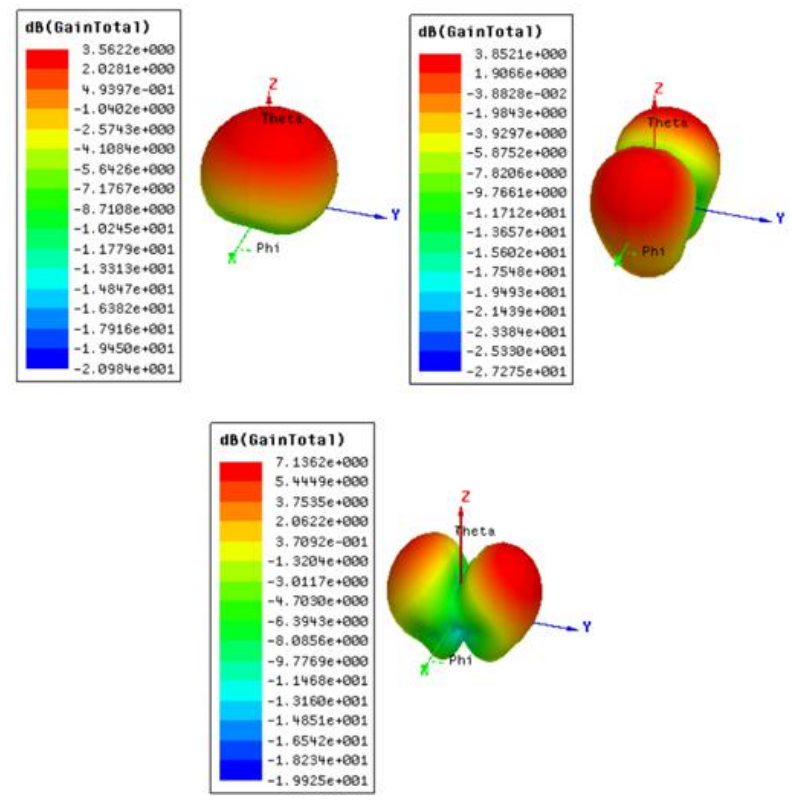

Figure 11: 3D gain plot of 0th iteration of proposed antenna

The simulated gain is also observed at every resonant frequency for all the iterations of proposed antenna. $0^{\text {th }}$ iteration shows the value of gain as $3.56 \mathrm{~dB}, 3.85 \mathrm{~dB}$ and $7.13 \mathrm{~dB}$ and their respective frequency bands are $3.89 \mathrm{GHz}$, $6 \mathrm{GHz}$ and $7.80 \mathrm{GHz} .1^{\text {st }}$ iteration shows the value of gain as $2.84 \mathrm{~dB}$ and $3.94 \mathrm{~dB}$ for respective frequency bands such as $3.86 \mathrm{GHz}$ and $7.99 \mathrm{GHz}$. Similarly, $2^{\text {nd }}$ iteration shows the value of gain as $3.19 \mathrm{~dB}, 2.61 \mathrm{~dB}, 3.44 \mathrm{~dB}$ and $11.53 \mathrm{~dB}$ and their respective frequency bands are $2.36 \mathrm{GHz}, 3.11 \mathrm{GHz}$, 
$5.53 \mathrm{GHz}$ and $9.86 \mathrm{GHz}$. The value of gain at every frequency band is at acceptable level and 3D gain plot for all the iterations is shown in Figure 11, Figure 12 and Figure 13 respectively.

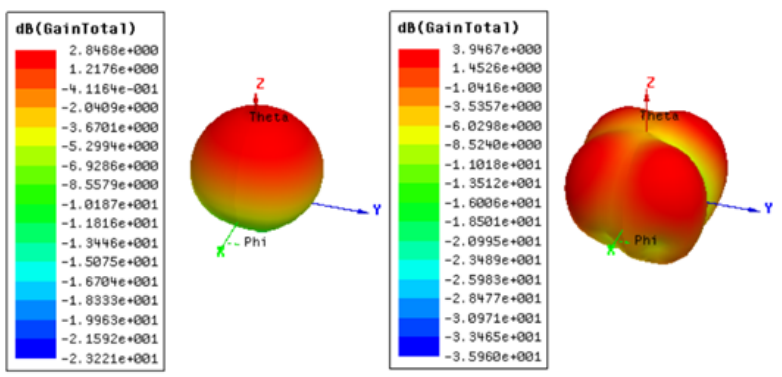

Figure 12: 3D gain plot of $1^{\text {st }}$ iteration of proposed antenna
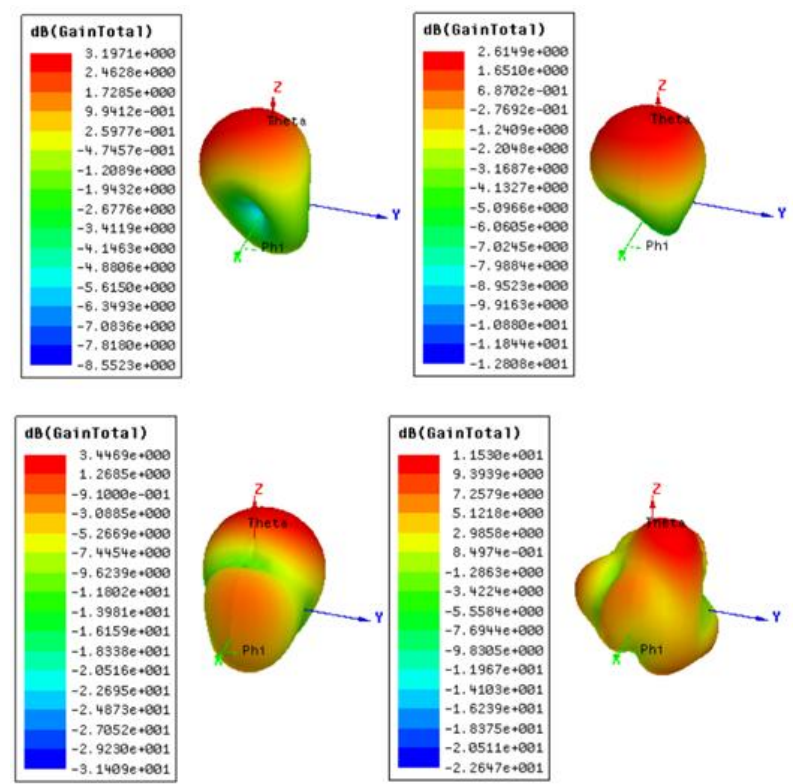

Figure 13: 3D gain plot of 2nd iteration of proposed antenna

\section{CONCLUSIONS}

Novel design of fractal antenna using Giuseppe peano geometry for wireless applications has been presented in this paper. Three iterations of proposed antenna have been designed to achieve the miniaturization of antenna. The operating frequency of the antenna decreases on increasing the antenna iterations as shown in Table 2. The gain of antenna is also observed at all the frequency bands of designed antenna. This shows that the antenna can be useful for different wireless applications such as bluetooth (2.12$2.95 \mathrm{GHz})$, WLAN $(4.82-595 \mathrm{GHz})$, high speed wireless communication $(5.92 \mathrm{GHz}-8.5 \mathrm{GHz})$ and $\mathrm{X}$-band for satellite communication $(8-12 \mathrm{GHz})$.

\section{REFERENCES}

[1] B. Roy, A. Bhatacharya, A. K. Bhattacharjee and S. K. Chowdhury, "UWB monopole antenna design in different substrate using sierpinski carpet fractal geometry," IEEE $2^{\text {nd }}$ International Conference on Electronics and Communication System (ICECS), pp. 382-385, 2015

[2] J. S. Sivia and S. S. Bhatia, "Design of fractal based microstrip rectangular patch antenna for multiband applications," IEEE International Advance Computing Conference (IACC), pp. 712-715, 2015.

[3] G. Bharti, S. Bhatia and J. S. Sivia, "Analysis and design of triple band compact microstrip patch antenna with fractal elements for wireless applications," International Conference on Computational Modeling and Security (CMS 2016), Elsevier Procedia Computer Science, Vol. 85, pp. 380-385, 2016.

[4] A. Kaur and N. Sharma , "A quad band circular patch antenna with fractal elements for S-band and C-band applications," International Journal of Computer Applications, Vol. 144, No. 3, pp. 1-4, 2016.

[5] S. Behera and D. Barad, "A novel design of microstrip fractal antenna for wireless sensor network," IEEE International Conference on Computation of Power, Energy, Information and Communication, pp. 04700474,2015

[6] A. S. Wadekar and S. V. Khobragade, "Design of multiband monopole triangular fractal antenna for GSM, bluetooth and wi-fi," IEEE International Advance Computing Conference (IACC), pp. 988-991, 2015.

[7] T. Sarkar, J. Chakravorty and R. Ghatak, "Broadband fractal slot planar antenna," IEEE, 2015

[8] Y. Jia, Y. Liu and S. Gong, " Slot coupled broadband patch antenna," Electronics Letters, vol. 51, no. 6, pp. 445-447, 2015.

[9] A. R. Karade and P. L. Zade, "A miniaturized rectangular microstrip patch antenna using SSRR for WLAN applications," IEEE, ICCSP, pp. 1002-1004, 2015.

[10] I. Acharya and D. Upadhyay, "A novel ultra wideband antenna with dual band notches for wireless applications," International Conference on Electrical, Electronics, Signals, Communication and Optimization (EESCO), 2015.

[11] X. Hu, W. Yang, S. Yu and W. H. Liao, "Triple band notched UWB antenna with tapered microstrip feed line and slot coupling for bandwidth enhancement," $16^{\text {th }}$ International Conference on Electronic Packaging Technology, pp. 879-883, 2015 